\title{
Development of Highly Potent Carbazole Amphiphiles as Membrane-Targeting Antimicrobials for Treating Gram-Positive Bacterial Infections
}

Shuimu Lin, ${ }^{\dagger}$ Jiayong Liu, ${ }^{\dagger}$ Hongxia Li, ${ }^{\dagger}$ Ying Liu, ${ }^{\star}$ Yongzhi Chen, ${ }^{\dagger}$ Jiachun Luo, ${ }^{\dagger}$ Shouping Liu* ${ }^{* \dagger}$

†Key Laboratory of Molecular Target \& Clinical Pharmacology and the State Key Laboratory of Respiratory Disease, School of Pharmaceutical Sciences \& the Fifth Affiliated Hospital, Guangzhou Medical University, Guangzhou 511436, P.R. China ${ }^{\ddagger}$ Guangdong Key Laboratory of Optical Fiber Sensing and Communications, Institute of Photonics Technology, Jinan University, Guangdong, Guangzhou 510632, P.R. China

* Corresponding Author. Email address: liushouping2018@163.com 


\section{Table of Contents}

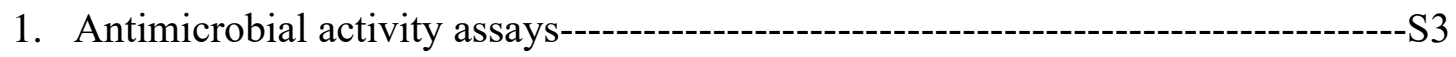

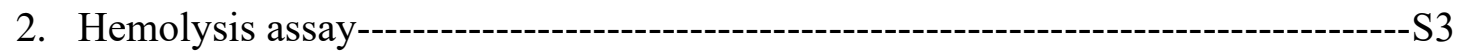

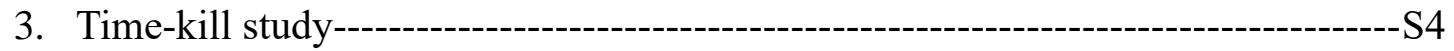

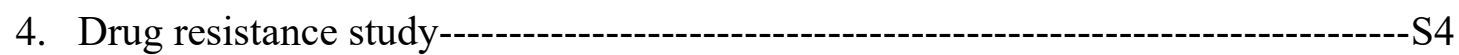

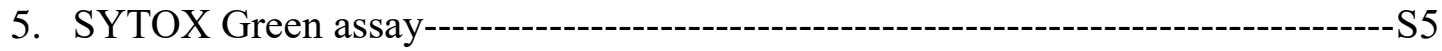

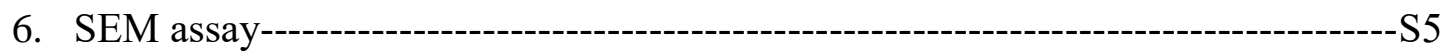

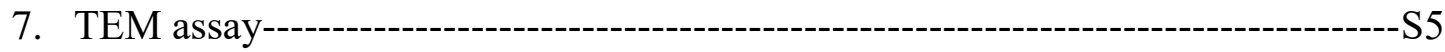

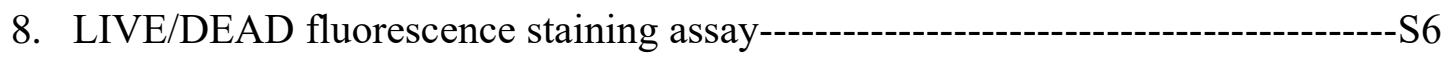

9. BODIPYTM_TR-cadaverine displacement assay--------------------------------------S6

10. CCK-8 assay---------------------------------------------------------------------------------S7

11. In vivo toxicity toward murine cornea via topical application---------------------S7

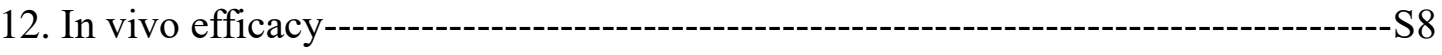

13. Table S1. MIC values of several active carbazole derivatives against various

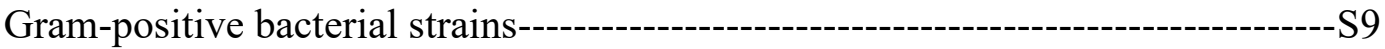

14. Figure S1. In vivo toxicity toward murine cornea of compound 29 via topical

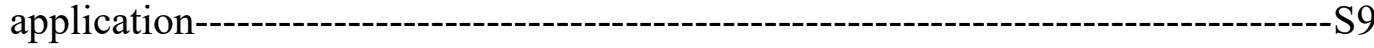

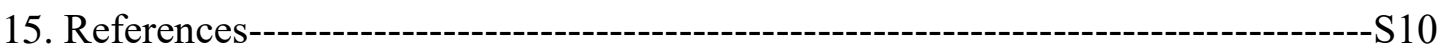

16. HPLC traces of the final carbazole compounds------------------------------------S11 
Antimicrobial Activity Assays. MIC determinations were performed according to the Clinical \& Laboratory Standards Institute (CLSI) guidelines. Compounds were dissolved in $\mathrm{DMSO} / \mathrm{H}_{2} \mathrm{O}$ to prepare $1000 \mu \mathrm{g} / \mathrm{mL}$ stock solutions (final DMSO concentration of $\leq 2.5 \%$ ). The stock solution was serially diluted with Muller Hinton Broth (MHB). The bacteria were incubated on Mueller-Hinton agar (MHA) plates at $37^{\circ} \mathrm{C}$ for 24 hours, and then the inoculum was adjusted to approximately $10^{6} \mathrm{CFU} / \mathrm{mL}$. The bacterial suspension $(100 \mu \mathrm{L})$ was mixed with two-fold serial dilutions of compounds $(100 \mu \mathrm{L})$ in 96-well plate (final compound concentrations of 50, 25, 12.5, $6.25,3.125,1.56,0.78,0.39 \mu \mathrm{g} / \mathrm{mL})$. After $24 \mathrm{~h}$ incubation at $37^{\circ} \mathrm{C}$, the absorption wavelength of the mixture was read at $600 \mathrm{~nm}$ using a Biotek multi-detector microplate reader. The MIC value was defined as the lowest concentration of compound to inhibit the growth of bacteria. The experiments were performed at least twice with two duplicates for each time and with biological replicates.

Hemolysis Assay. The hemolysis experiment was carried out as described in our previous reports. ${ }^{1,2}$ Briefly, rabbit red blood cells (RBCs) were centrifuged at $2500 \mathrm{rpm}$ for 3 minutes and washed twice with PBS, then was suspended in PBS $(\mathrm{pH}=7.2)$ to make a $8 \% \mathrm{v} / \mathrm{v}$ RBCs suspension. The RBCs suspension was incubated with an equal volume of two-fold serial dilutions of compounds $(100 \mu \mathrm{L})$ at $37^{\circ} \mathrm{C}$ for 1 hours. The mixture was centrifuged at $2500 \mathrm{rpm}$ for $5 \mathrm{~min}$, and then supernatant $(100 \mu \mathrm{L})$ was transferred into a 96-well plate. The absorbance was read at $576 \mathrm{~nm}$ using a Biotek multi-detector microplate reader. The treatment of $2 \%$ Triton X-100 solution was used as a positive control, and the treatment of $0.5 \%$ DMSO was used as a negative control. 
Hemolytic activity was calculated by the following formula: $\%$ hemolysis $=\left[\left(\mathrm{Abs}_{\text {sample }}\right.\right.$ $\left.\left.-\mathrm{Abs}_{\text {negative control }}\right) /\left(\mathrm{Abs}_{\text {positive control }}-\mathrm{Abs}_{\text {negative control }}\right)\right] \times 100$. The experiments were performed at least twice with three duplicates for each time and with biological replicates.

Time-Kill Study. The in vitro time-kill kinetics of compound 29 and vancomycin were performed against S. aureus ATCC29213. The bacteria were incubated on MHA plates at $37{ }^{\circ} \mathrm{C}$ for 24 hours, and then the inoculum was adjusted to approximately $10^{6}$ $\mathrm{CFU} / \mathrm{mL}$. The bacterial suspension was incubated with samples at different concentrations $(4 \times$ and $8 \times \mathrm{MIC})$ at $37^{\circ} \mathrm{C}$. The aliquots were then removed from the mixtures at different time points $(0.5,1,2,4,8$, and $24 \mathrm{~h})$, and were serially diluted 10 fold in PBS $(\mathrm{pH}=7.2)$ and plated with MHA medium. The plates were incubated for 24 hours at $37^{\circ} \mathrm{C}$. The bactericidal efficacy of the compounds was evaluated by counting the bacterial colonies grown on the plates. The experiments were carried out at least twice and with biological replicates.

Drug Resistance Study. The initial MICs for the compounds against S. aureus ATCC29213 were obtained according to the above method. The bacteria from the wells at $0.5 \times$ MIC concentration were then used to prepare the bacterial suspension for the next MIC value test. The experiment was repeated every day for 21 days.

SYTOX Green Assay. S. aureus ATCC29213 or MRSA NCTC10442 were incubated at $37{ }^{\circ} \mathrm{C}$ overnight. The inoculum was washed three times with PBS ( $\left.\mathrm{pH}=7.2\right)$ and resuspended in PBS to prepare bacterial suspension $\left(\mathrm{OD}_{600}=0.2\right)$. The bacterial suspension was cultured in darkness with $0.3 \mu \mathrm{M}$ SYTOX Green dye. The fluorescence 
intensity of mixture was monitored by a Biotek multi-detector microplate reader (emission excitation and excitation wavelengths were 523 and $504 \mathrm{~nm}$, respectively). After the fluorescence signal had stabilized, the different concentrations $(1 \times, 2 \times, 4 \times$ and $8 \times$ MIC) of compound 29 (final DMSO concentration of $0.5 \%$ ) were added to the mixture, and the fluorescence intensity changes were monitored and recorded for about $1 \mathrm{~h}$. The experiments were performed at least twice with two duplicates for each time and with biological replicates.

SEM Assay. S. aureus ATCC29213 was incubated to the logarithmic growth phase, then suspended in PBS buffer $(\mathrm{pH}=7.2)$ and adjusted to approximately $5 \times 10^{7} \mathrm{CFU} / \mathrm{mL}$. The bacterial suspension was then mixed with compound 29 (final concentration $=8 \times$ MIC) and incubated at $37^{\circ} \mathrm{C}$ for 2 hours. The PBS treated group was used a negative control. After centrifugation at $5000 \mathrm{rmp}$ for $5 \mathrm{~min}$, the cell pellets were collected, washed with PBS twice, and fixed with $2.5 \%$ glutaraldehyde at $4{ }^{\circ} \mathrm{C}$ overnight. Subsequently, the collected cell pellets were washed with fresh PBS, dehydrated with different gradients of ethanol $(30 \%, 50 \%, 70 \%, 90 \%, 95 \%)$, and treated with acetone three times and washed with tert-butanol twice. Finally, the cell pellets were dried in vacuum. The prepared samples were analyzed by a Thermo Scientific Apreo. The experiments were performed at least twice with biological replicates.

TEM Assay. S. aureus ATCC29213 was incubated to the logarithmic growth phase, then suspended in PBS buffer and adjusted to approximately $5 \times 10^{7} \mathrm{CFU} / \mathrm{mL}$. The bacterial suspension was then mixed with compound $\mathbf{2 9}($ final concentration $=8 \times$ MIC) and incubated at $37{ }^{\circ} \mathrm{C}$ for $2 \mathrm{~h}$. The PBS treated group was used a negative control. 
After centrifugation at $5000 \mathrm{rmp}$ for $5 \mathrm{~min}$, the cell pellets were collected, washed with PBS twice, and fixed with $2.5 \%$ glutaraldehyde at $4{ }^{\circ} \mathrm{C}$ overnight. Subsequently, the collected cell pellets were washed with fresh PBS and prepared into a suspension. Then the bacteria suspension was dropped onto the copper mesh. After being dried, the copper mesh was stained with $2 \%$ sodium phosphotungstate aqueous for $1 \mathrm{~min}$. After being dried, the copper mesh was used in the TEM study. TEM images were observed by TEM (JEOL JEM-1400Plus). The experiments were performed at least twice with biological replicates.

LIVE/DEAD Fluorescence Staining Assay. LIVE/DEAD ${ }^{\mathrm{TM}}$ Bac Light $^{\mathrm{TM}}$ bacterial viability kits L7007 (ThermoFisher, USA) was used to determine the membrane integrity of bacteria. S. ATCC29213 was incubated to the logarithmic growth phase, then was centrifuged at $5000 \mathrm{rpm}$ for $5 \mathrm{~min}$, and the supernatant was removed. The bacterial cells were washed twice with PBS $(10 \mathrm{mM}, \mathrm{pH}=7.2)$, and resuspended in PBS buffer to obtain the bacterial cell density of approximately $1 \times 10^{8} \mathrm{CFU} / \mathrm{mL}$. The bacterial suspension was mixed with compound 29 (final concentration $=8 \times$ MIC) or PBS (negative control) and incubated for 2 hours at $37{ }^{\circ} \mathrm{C}(150 \mathrm{rpm})$. Then, every sample was incubated with Syto $9(5 \mu \mathrm{M})$ and PI $(30 \mu \mathrm{M})$ for 15 min in the dark. Finally, the bacterial cells were prepared into smears and were observed under a laser confocal microscope (ZEISS LSM 880). The experiments were performed at least twice with biological replicates.

BODIPYTM-TR-cadaverine Displacement Assay. BODIPYTM-TR-cadaverine displacement assay was used to determine the binding affinity between compound $\mathbf{2 9}$ 
and lipoteichoic acid (LTA). BODIPYTM-TR-cadaverine was obtained from ThermoFisher, and LTA from Bacillus subtilis was purchased from Sigma-Aldrich. Fluorescence intensity of probe was quenched when probe was bound to LTA. When the probe is replaced and re-dissolved in the solution, the fluorescence will be significantly enhanced. BODIPYTM-TR-cadaverine (final concentration of $5 \mu \mathrm{M}$ ) was mixed with LTA (final concentration of $12.5 \mu \mathrm{g} / \mathrm{mL}$ ) using Tris buffer (50 mM, pH 7.4) in 24-well plates. After 15 min, compound $29(1 \times, 2 \times, 4 \times$ and $8 \times$ MIC) was added, then mixture was kept for 30 min at room temperature in the dark. Finally, fluorescence intensity was measured using a Biotek multi-detector microplate reader (excitation wavelength of $580 \mathrm{~nm}$ and emission wavelength of $620 \mathrm{~nm}$ ). The experiments were performed at least twice with biological replicates.

CCK-8 Assay. The cytotoxicity of compound 29 toward mouse corneal epithelial cells or mouse macrophage J774A.1 cells was determined using CCK-8 assay, according to previously reported method. ${ }^{3,4}$ The incubation time with compound 29 was 24 hours. All measurements were performed with biological replicates.

In Vivo Toxicity toward Murine Cornea via Topical Application. All in vivo toxicity animal experiments were approved by the Laboratory Animal Center of Guangzhou Medical University and carried out in accordance with the policy of the Ministry of Health. Female C57BL6 mice (6-8 weeks, average weight $20 \mathrm{~g}$ ) were used in this study. These mice were randomly divided into 3 groups (three mice per group). 29 were given four times every day for three days. The treatment with $5 \%$ dextrose was used as a negative control. The corneas that were scratched with a sterile needle were used as a 
positive control. After the third day of administration, $1 \%$ fluorescein sodium solution (dissolved in $0.9 \%$ saline) was used to stain the cornea. Fluorescein sodium was widely used for the clinical examination of corneal surface damage. ${ }^{5,6}$ All photographs were observed under a slit-lamp biomicroscope equipped with a cobalt blue filter.

In Vivo Efficacy. All animal experiments were approved by the Laboratory Animal Center of South China Agricultural University and carried out in accordance with the policy of the Ministry of Health. Female C57BL6 mice (6-8 weeks, average weight 20 g) obtained from SPF (Beijing) Biotechnology Co., Ltd. were used in this study. S. aureus ATCC29213 cells were grown $24 \mathrm{~h}$ on MHA plates at $37{ }^{\circ} \mathrm{C}$. Then, the concentration of bacterial suspensions was adjusted with PBS to $\sim 5 \times 10^{7} \mathrm{CFU} / \mathrm{mL}$ for use in murine corneal infection.

The mice were immunosuppressed using cyclophosphamide (100 $\mathrm{mg} / \mathrm{kg})$ via intraperitoneal injection 3 times in 5 days before infection. Tribromoethanol (500 mg) was dissolved in tert-amyl alcohol $(310 \mu \mathrm{L})$ to prepare $100 \%$ avertin stock solution. Then the $100 \%$ avertin stock solution was diluted with $0.9 \%$ saline to prepare $2.5 \%$ avertin solution as an anesthetic. The mice were anesthetized by intraperitoneal injection of $2.5 \%$ avertin solution $(500 \mathrm{mg} / \mathrm{kg})$. The right corneal scratches were created by sterile needles. Then $15 \mu \mathrm{L}$ of bacterial inoculum (S. aureus ATCC29213) was dripped onto the injured cornea. These mice were randomly divided into 3 groups, five mice per group $(n=5)$. The treatment began one day after infection. The corresponding drugs were given four times every day for three days. After the third day of topical administration, the mice were killed, the eyeballs were removed. The number of living 
bacteria on the cornea was counted by a standard plate counting method using MHA plates. Statistical significance was calculated by the SPSS 22.0 software. $P$ values were calculated by the independent $t$ test, and $P<0.05$ was considered significant.

Table S1. MIC values of several active carbazole derivatives against various Grampositive bacterial strains.

\begin{tabular}{lllll}
\hline & \multicolumn{3}{c}{$\mathrm{MIC}(\mu \mathrm{g} / \mathrm{mL})$} \\
\cline { 2 - 5 } Compd & B. subtilis & B. subtilis & S. epidermidis & S. epidermidis \\
& ATCC6633 & CMCC63501 & ATCC12228 & CMCC26069 \\
\hline $\mathbf{1 0}$ & 6.25 & 6.25 & 12.5 & 12.5 \\
$\mathbf{1 3}$ & 6.25 & 6.25 & 6.25 & 6.25 \\
$\mathbf{1 4}$ & 6.25 & 3.125 & 6.25 & 12.5 \\
$\mathbf{1 7}$ & 6.25 & 3.125 & 3.125 & 3.125 \\
$\mathbf{2 2}$ & 3.125 & 3.125 & 3.125 & 3.125 \\
$\mathbf{2 3}$ & 6.25 & 6.25 & 3.125 & 3.125 \\
$\mathbf{2 4}$ & 6.25 & 3.125 & 3.125 & 3.125 \\
$\mathbf{2 8}$ & 12.5 & 6.25 & 12.5 & 6.25 \\
$\mathbf{2 9}$ & 1.56 & 1.56 & 1.56 & 1.56 \\
$\mathbf{3 0}$ & 6.25 & 6.25 & 6.25 & 3.125 \\
$\mathbf{3 1}$ & 0.78 & 0.78 & 1.56 & 0.78 \\
$\mathbf{3 4}$ & 6.25 & 6.25 & 6.25 & 6.25 \\
$\mathbf{3 5}$ & 3.125 & 3.125 & 3.125 & 3.125 \\
\hline
\end{tabular}

A.

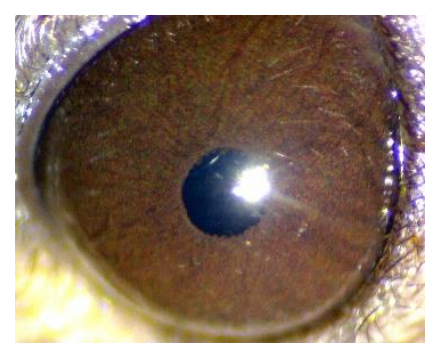

B.

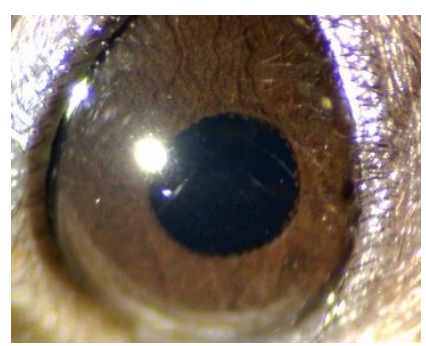

C.

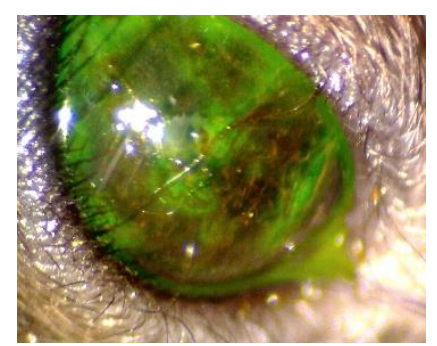

Figure S1. In vivo toxicity toward murine cornea of compound 29 via topical application. A: the treatment with $0.5 \%$ compound 29 ; B: the treatment with $5 \%$ dextrose (negative control); C: the cornea was scratched with a sterile needle (positive control). Representative slit-lamp photographs for each group are shown. 


\section{REFERENCES}

1. Lin, S.; Koh, J. J.; Aung, T. T.; Lim, F.; Li, J.; Zou, H.; Wang, L.; Lakshminarayanan, R.; Verma, C.; Wang, Y.; Tan, D. T.; Cao, D.; Beuerman, R. W.; Ren, L.; Liu, Symmetrically substituted xanthone amphiphiles combat Gram-positive bacterial resistance with enhanced membrane selectivity. J. Med. Chem. 2017, 60, $1362-1378$.

2. Lin, S.; Koh, J. J.; Aung, T. T.; Sin, W. L. W.; Lim, F.; Wang, L.; Lakshminarayanan, R.; Zhou, L.; Tan, D. T. H.; Cao, D.; Beuerman, R. W.; Ren, L.; Liu, S. Semisynthetic flavone-derived antimicrobials with therapeutic potential against Methicillin-resistant Staphylococcus aureus (MRSA). J. Med. Chem. 2017, 60, 6152-6165.

3. Guan, D.; Chen, F.; Xiong, L.; Tang, F.; Faridoon; Qiu, Y.; Zhang, N.; Gong, L.; Li, J.; Lan, L.; Huang, W. Extra sugar on vancomycin: new analogues for combating multidrug-resistant Staphylococcus aureus and vancomycin-resistant Enterococci. $J$. Med. Chem. 2018, 61, 286-304.

4. Tominaga, H.; Ishiyama, M.; Ohseto, F.; Sasamoto, K.; Hamamoto, T.; Suzuki, K.; Watanabe, M. A water-soluble tetrazolium salt useful for colorimetric cell viability assay. Anal. Commun. 1999, 36, 47-50.

5. Brazzell, R. K.; Stern, M. E.; Aquavella, J. V.; Beuerman, R. W.; Baird, L. Human recombinant epidermal growth factor in experimental corneal wound healing. Invest. Ophthalmol. Vis. Sci. 1991, 32, 336-340.

6. Zou, H., Koh, JJ, Qiu, SX, Beuerman, RW. Design and synthesis of amphiphilic xanthone-based, membrane-targeting antimicrobials with improved membrane selectivity. J. Med. Chem. 2013, 6, 2359-2373. 
HPLC traces of the final carbazole compounds

HPLC trace of 2

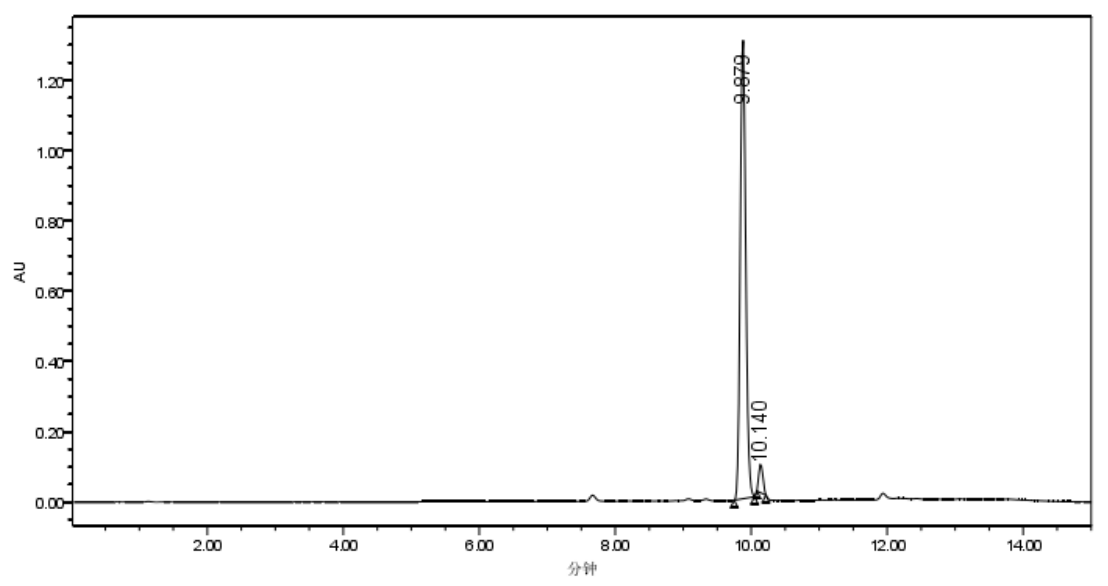

HPLC trace of $\mathbf{3}$

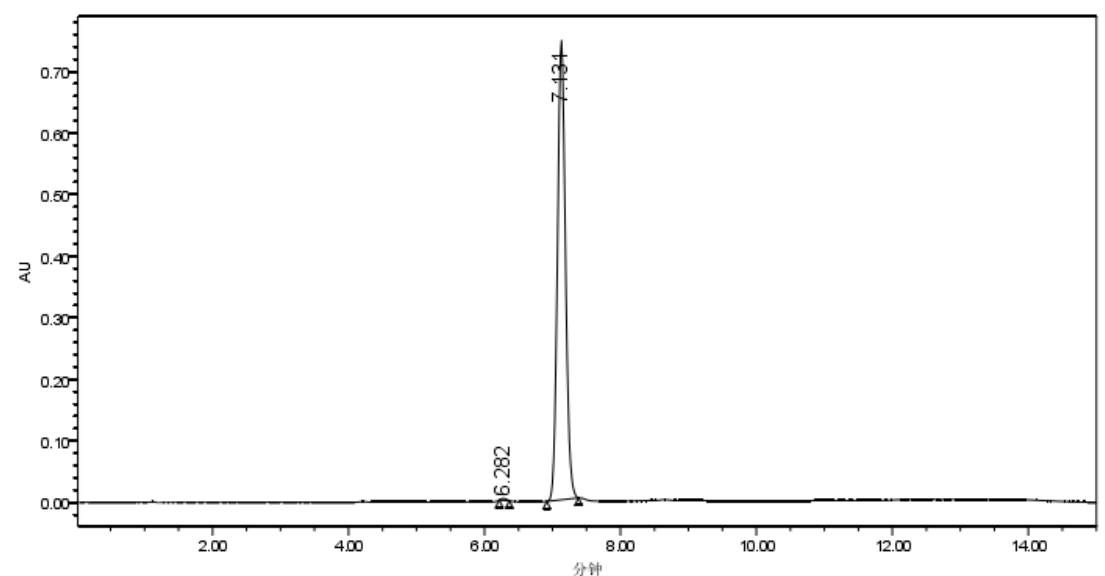

HPLC trace of 4

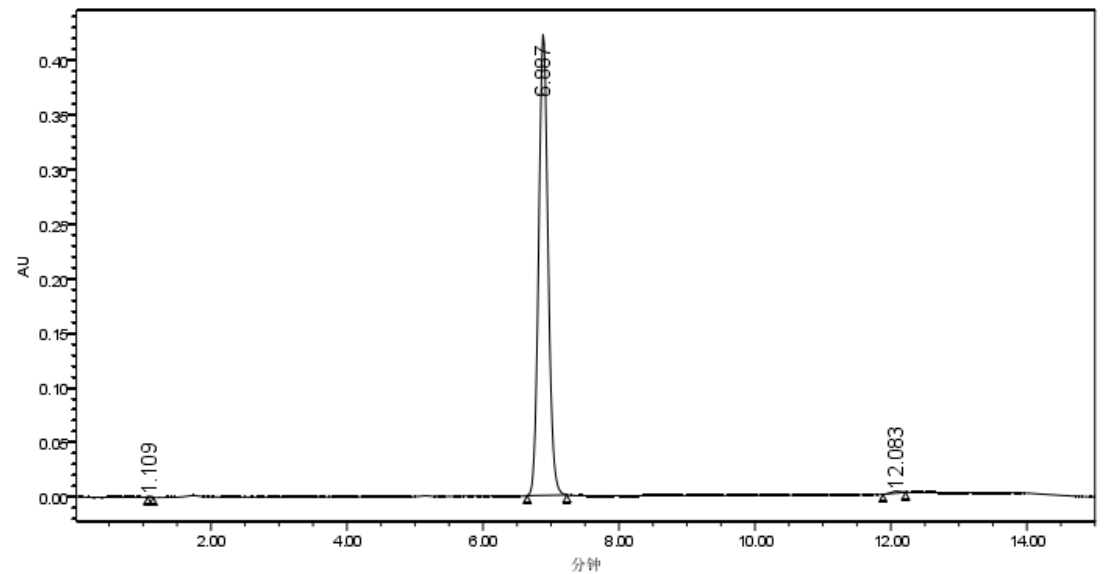


HPLC trace of 5

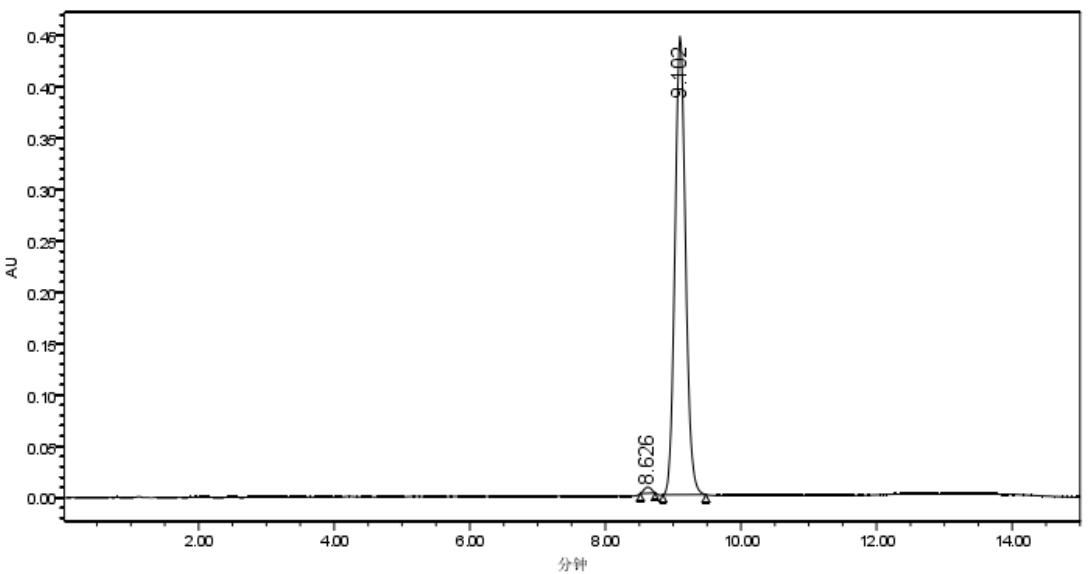

HPLC trace of 6

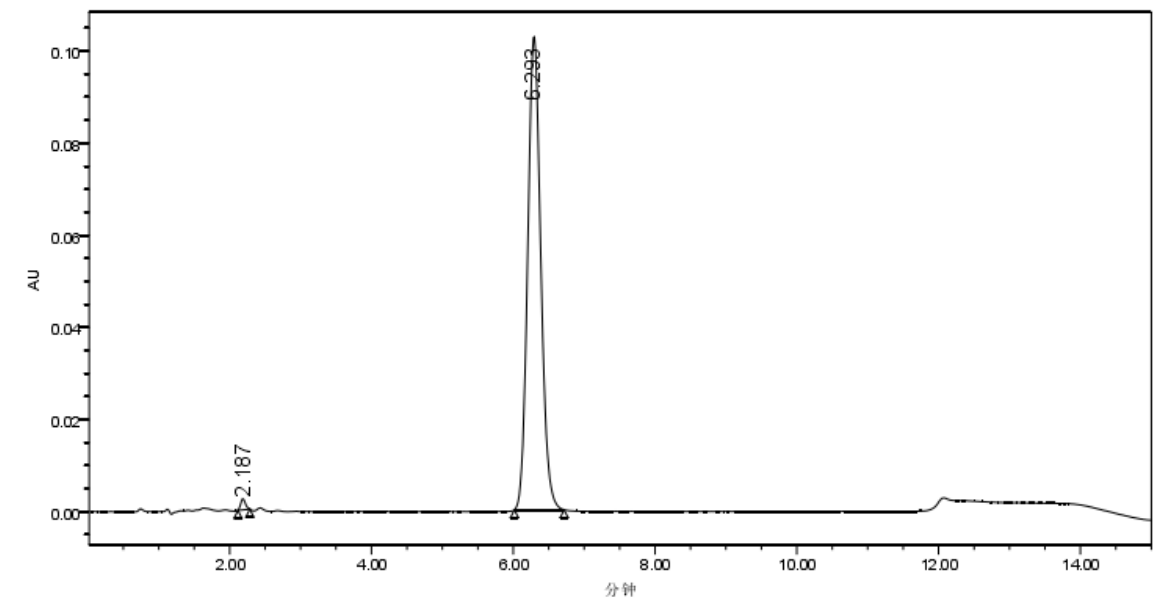

HPLC trace of 7

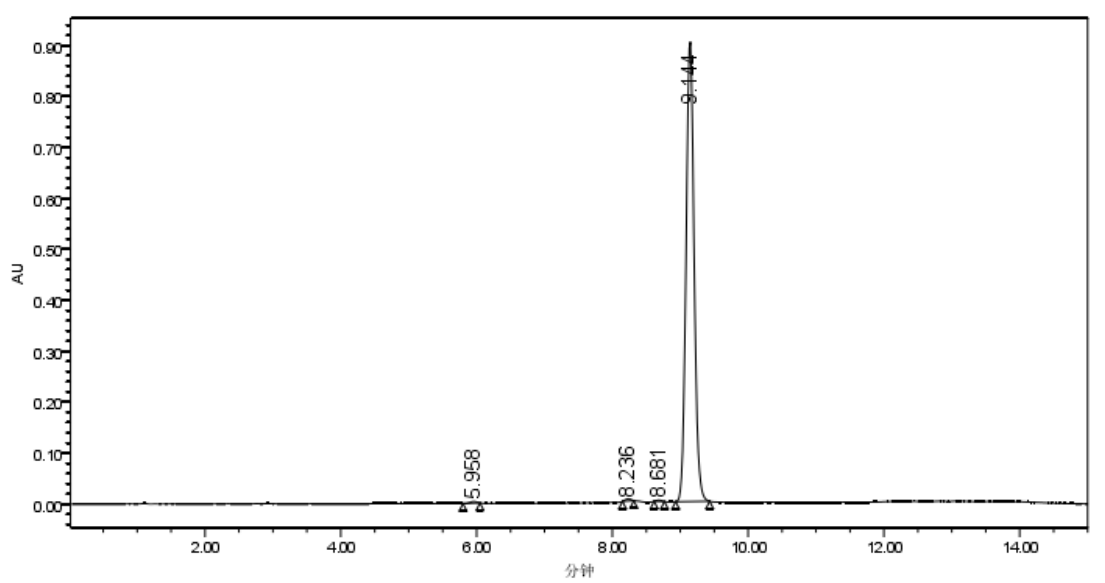


HPLC trace of 8

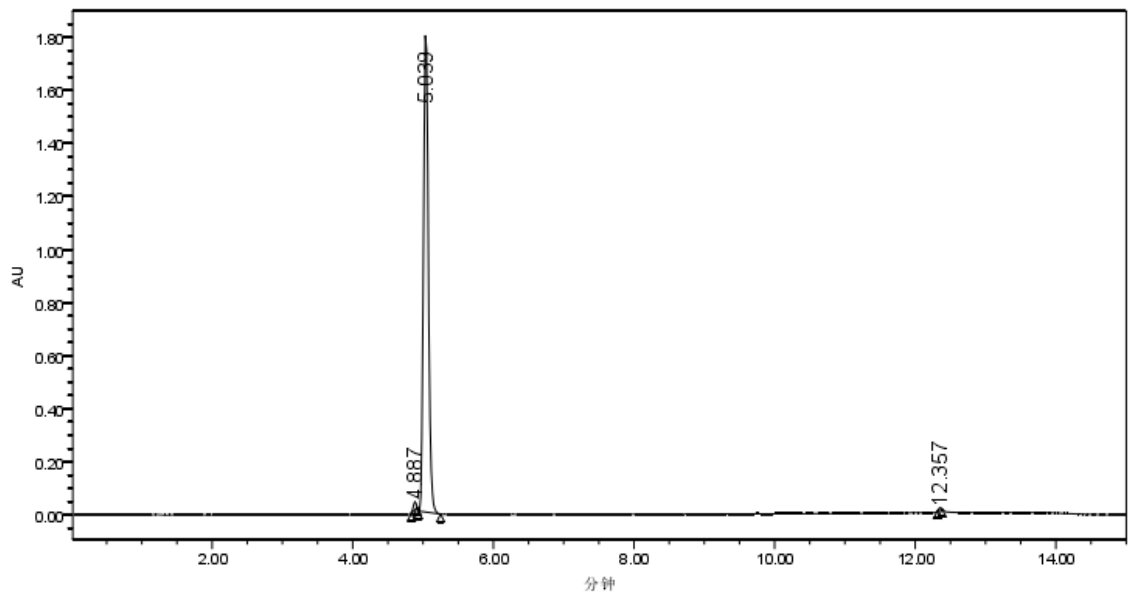

HPLC trace of 9

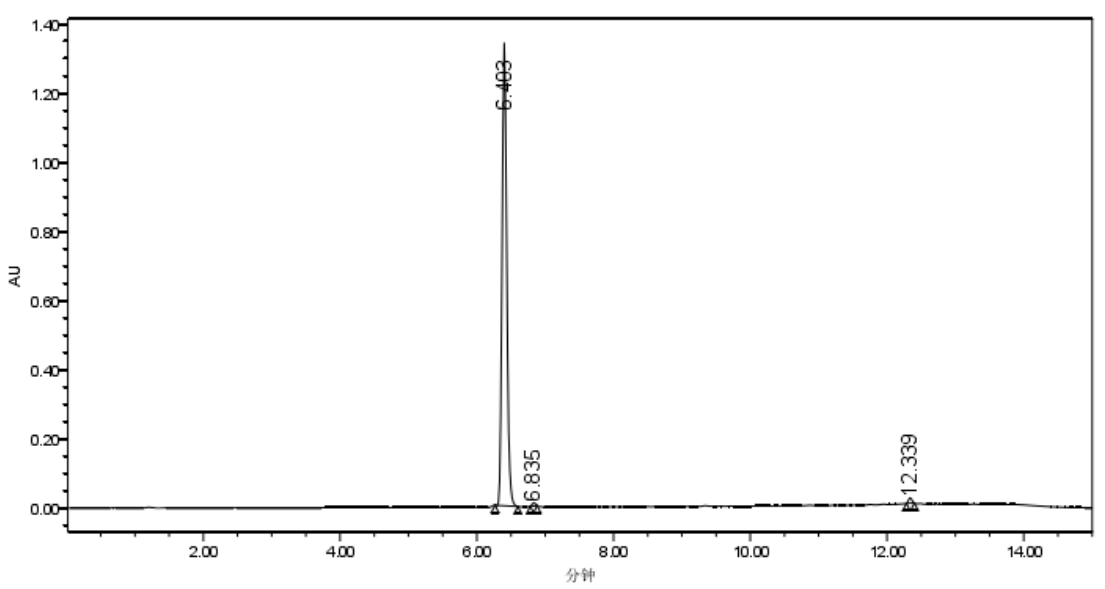

HPLC trace of $\mathbf{1 0}$

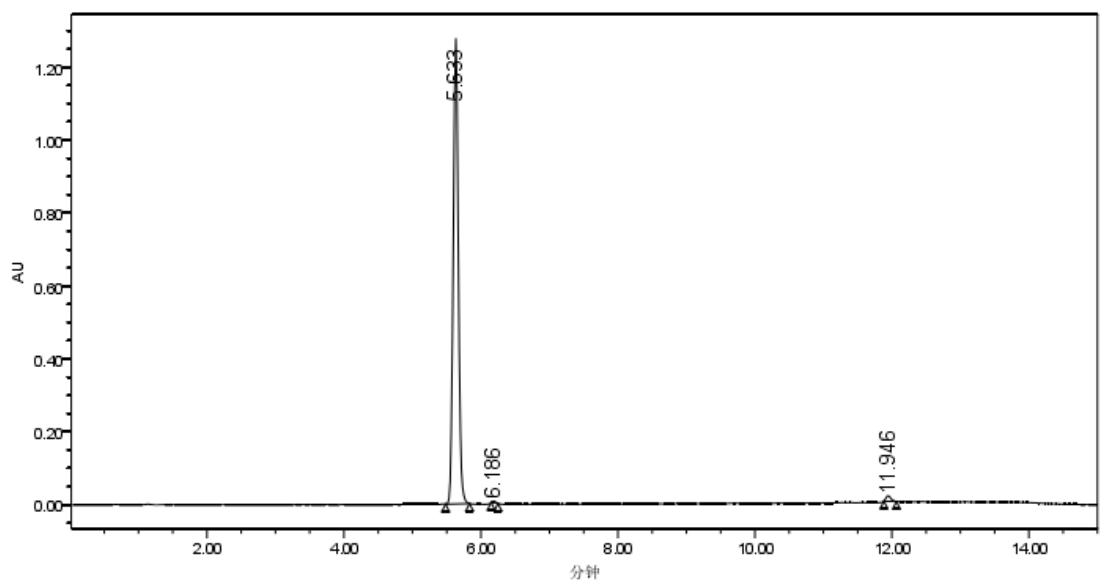


HPLC trace of $\mathbf{1 1}$

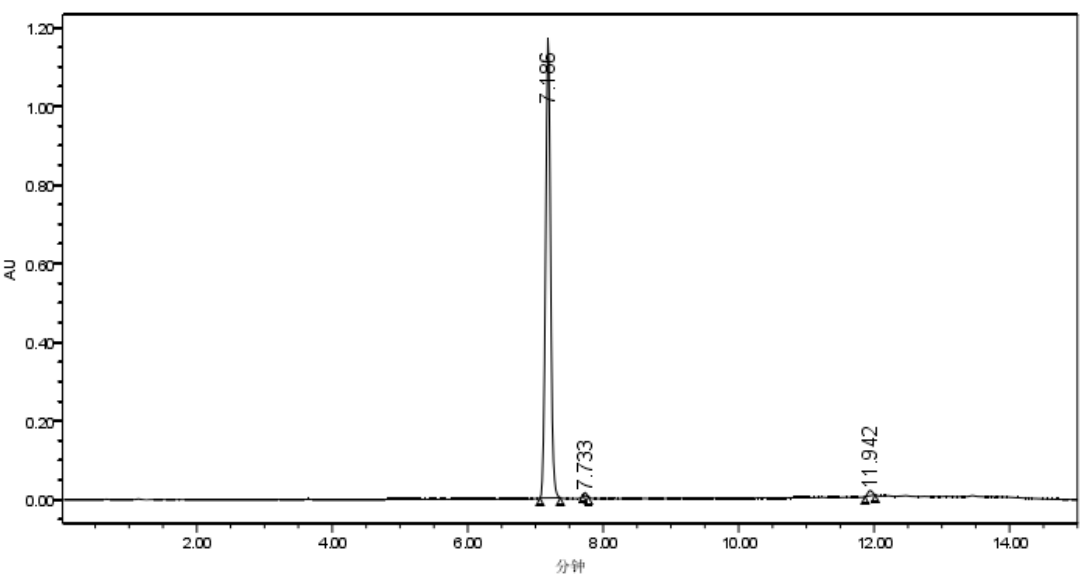

HPLC trace of $\mathbf{1 2}$

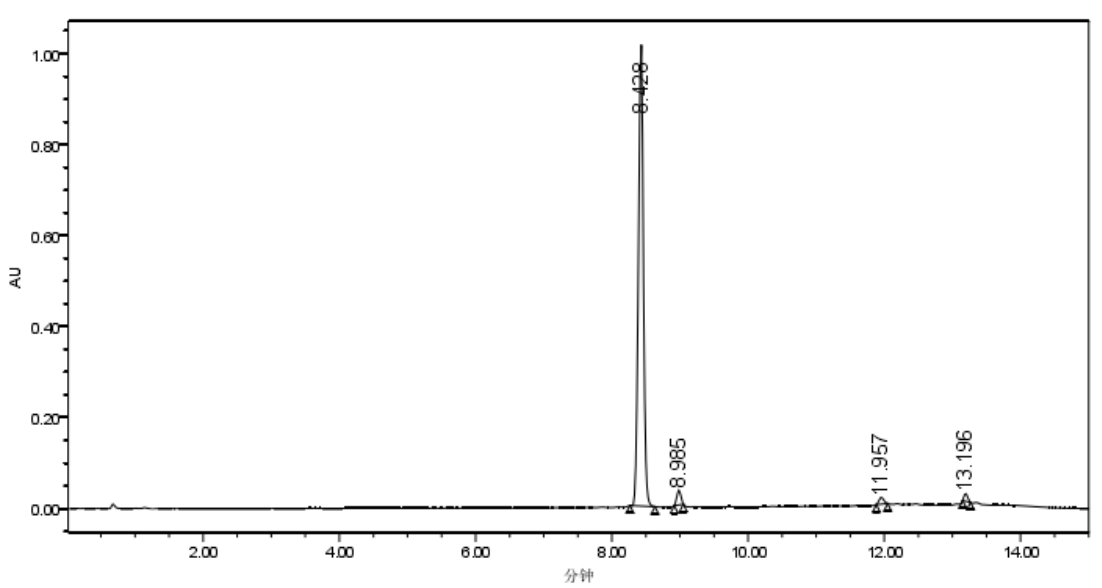

HPLC trace of $\mathbf{1 3}$

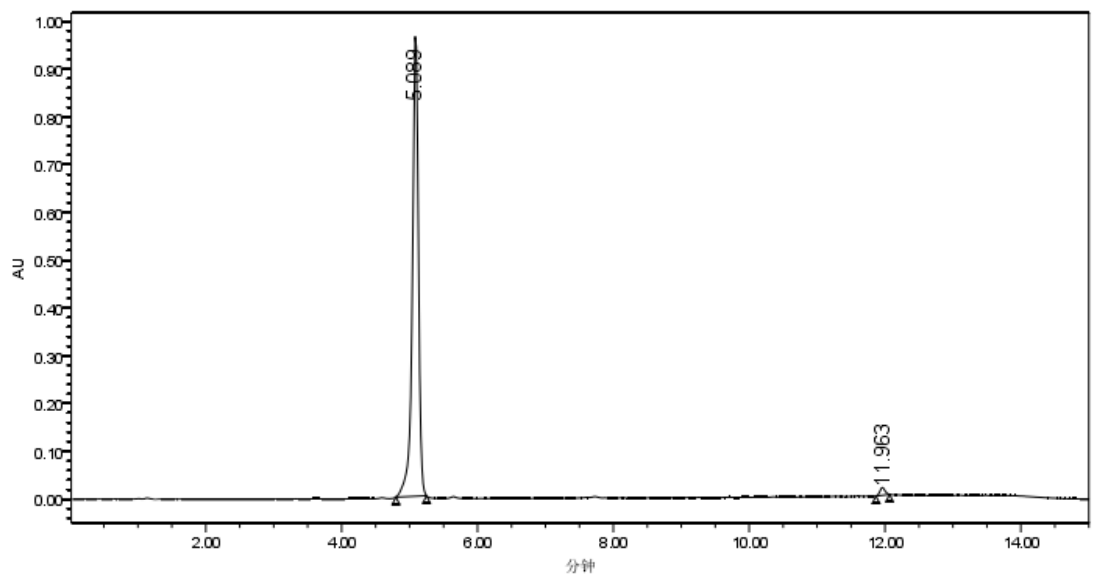




\section{HPLC trace of $\mathbf{1 4}$}

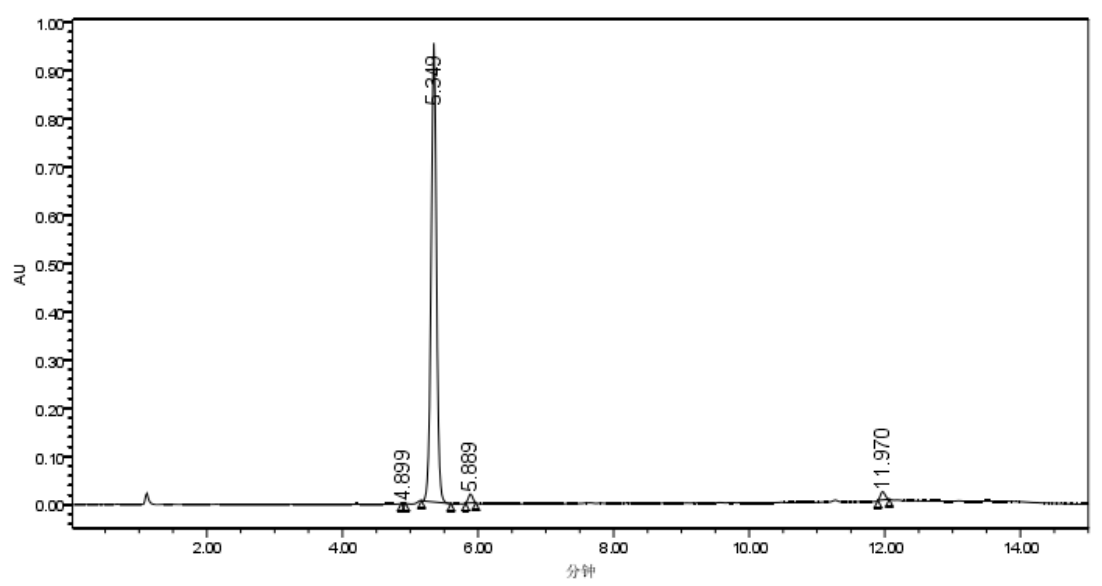

HPLC trace of $\mathbf{1 5}$

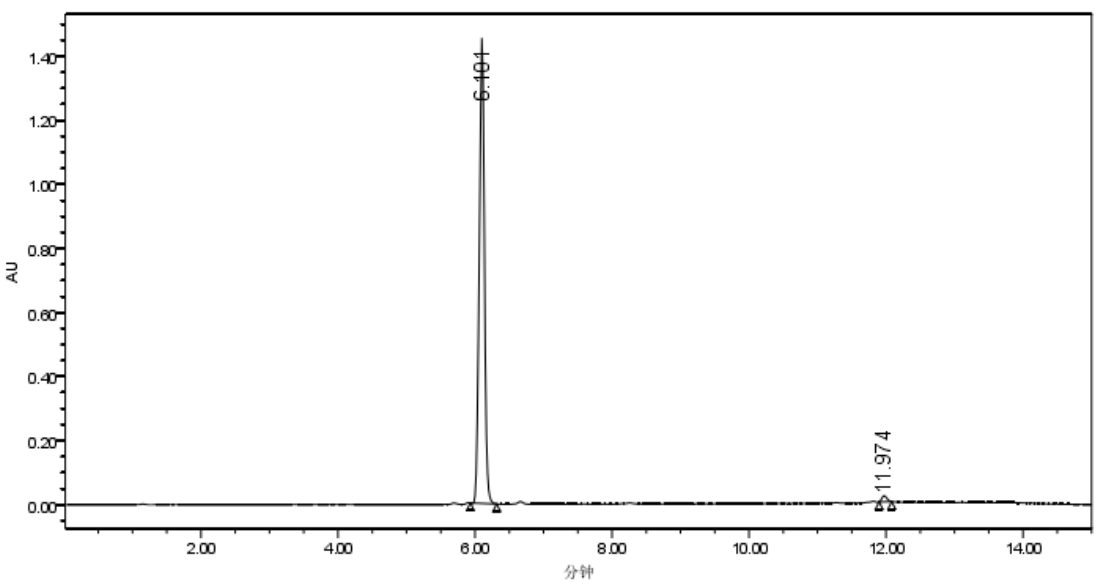

HPLC trace of $\mathbf{1 6}$

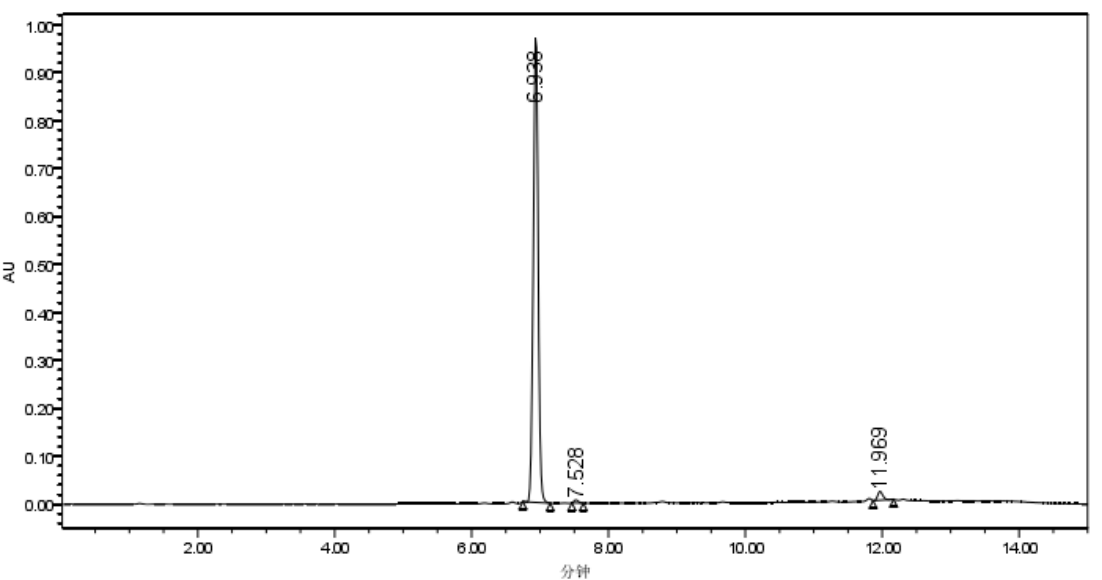


HPLC trace of $\mathbf{1 7}$

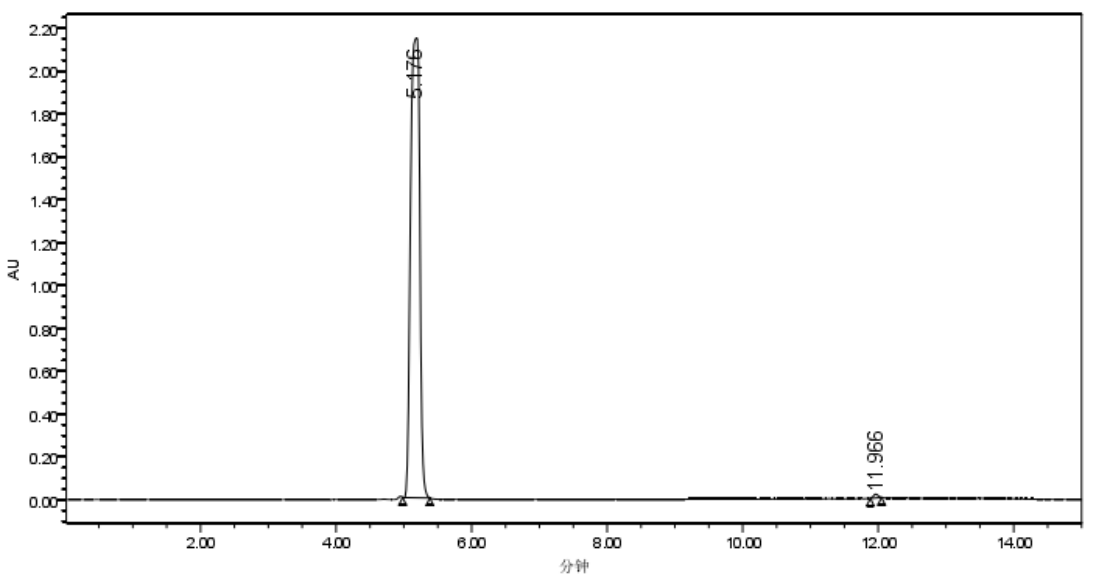

HPLC trace of $\mathbf{1 8}$

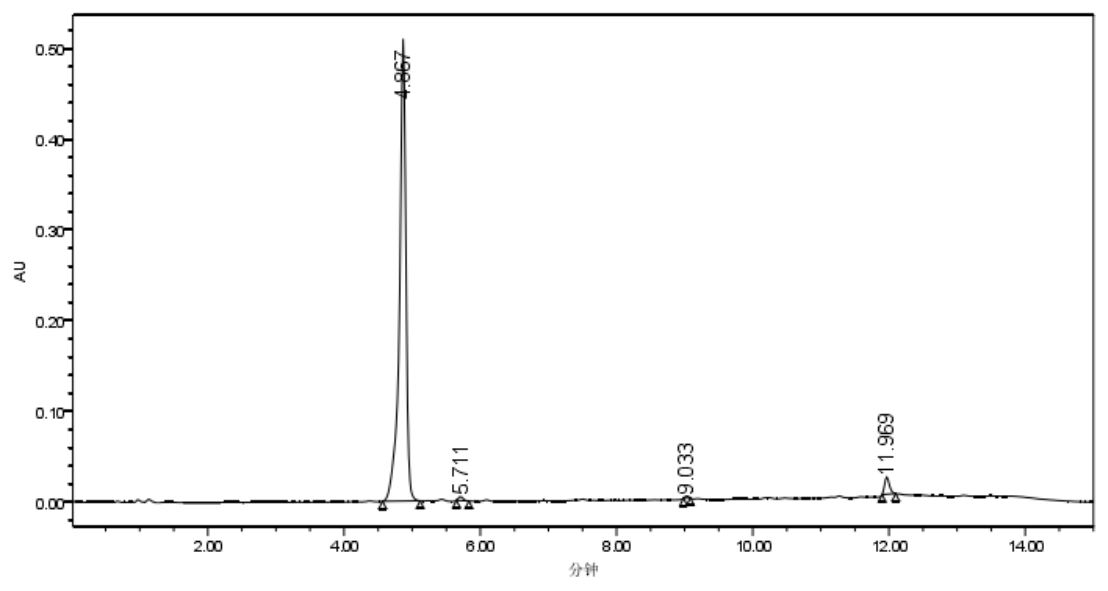

HPLC trace of 19

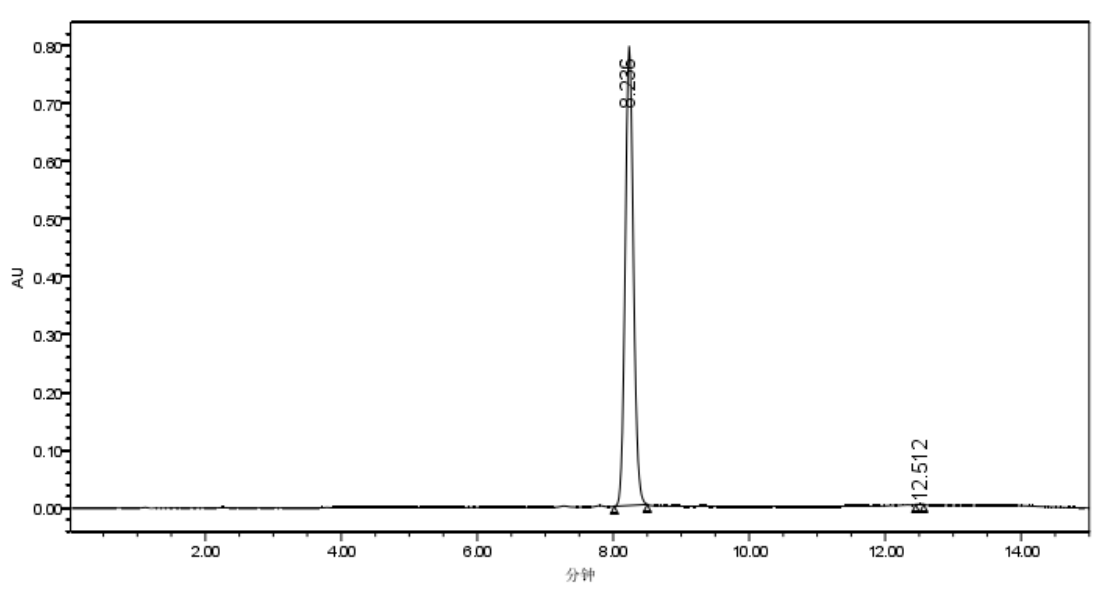


HPLC trace of $\mathbf{2 0}$

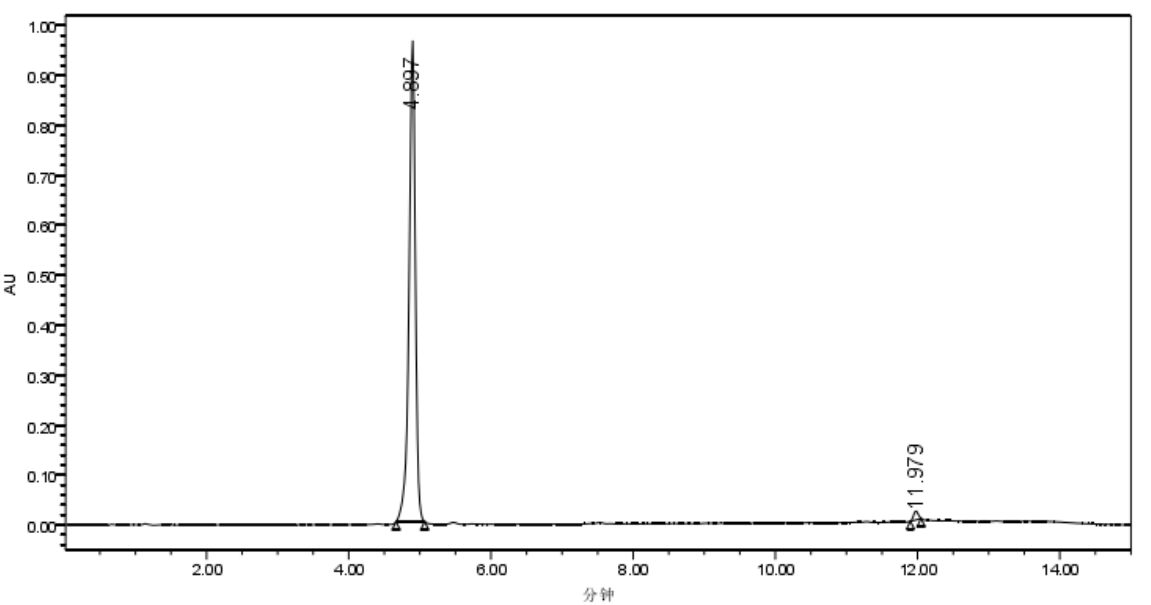

HPLC trace of $\mathbf{2 1}$

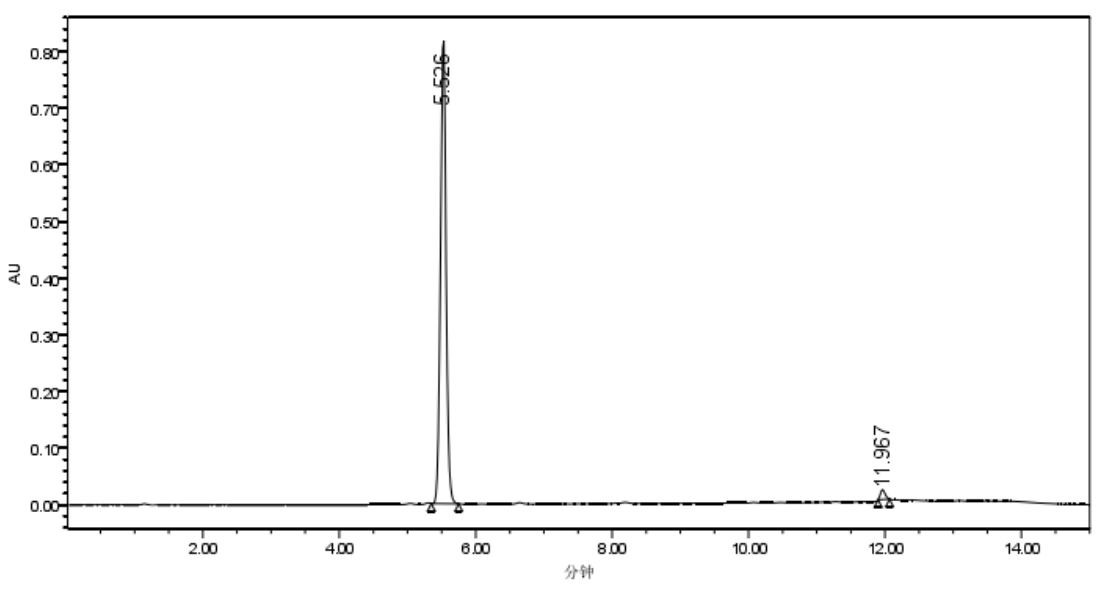

HPLC trace of $\mathbf{2 2}$

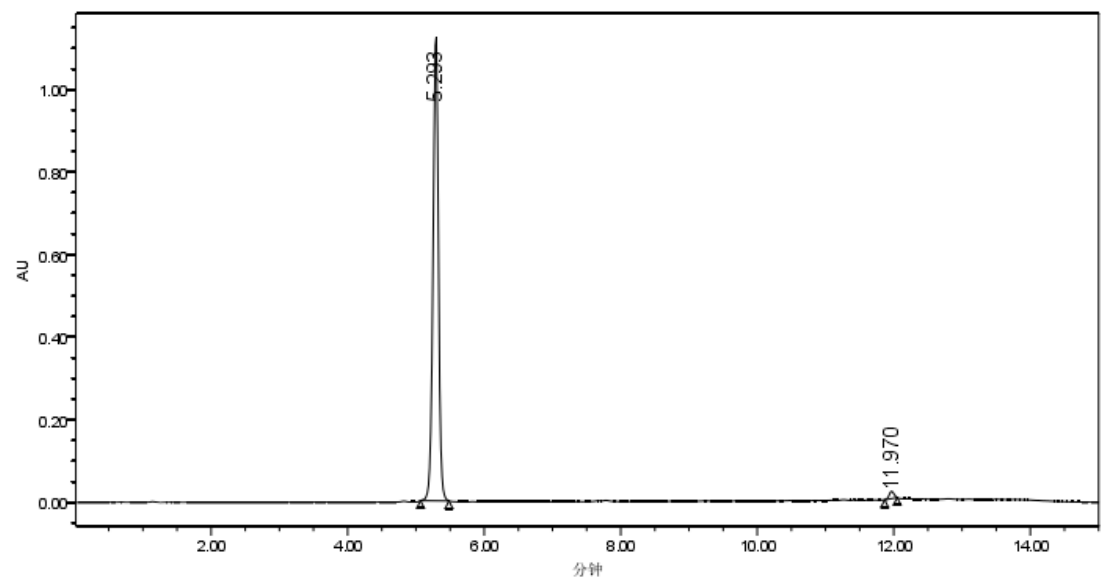


HPLC trace of $\mathbf{2 3}$

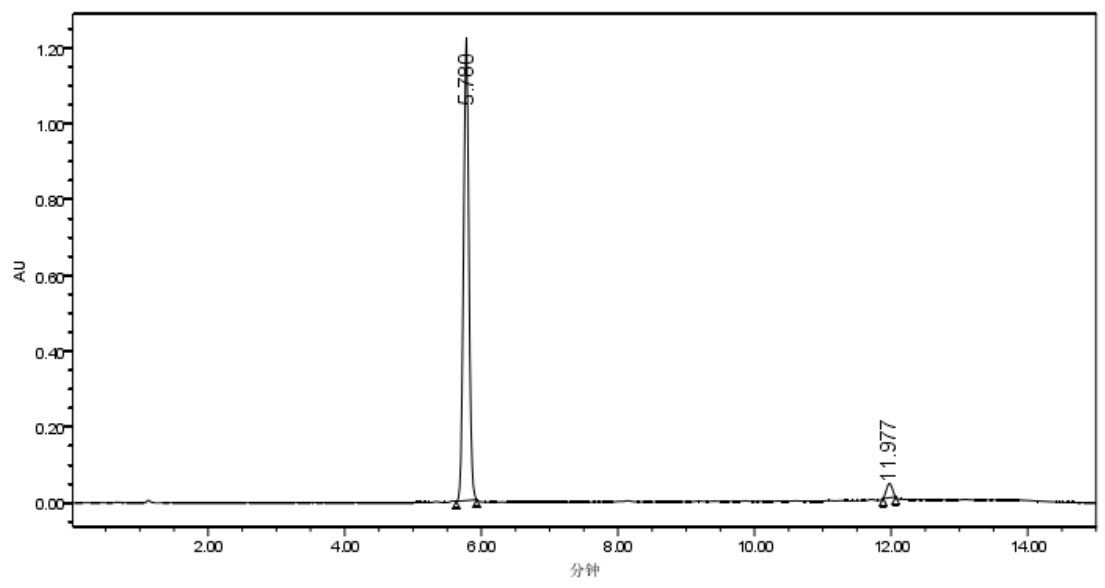

HPLC trace of $\mathbf{2 4}$

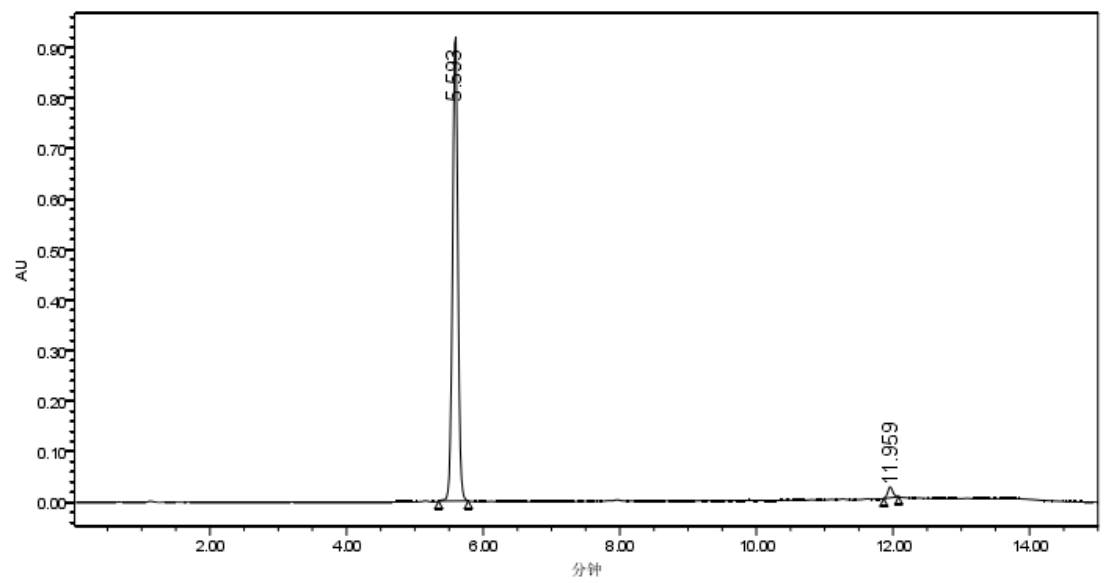

HPLC trace of $\mathbf{2 5}$

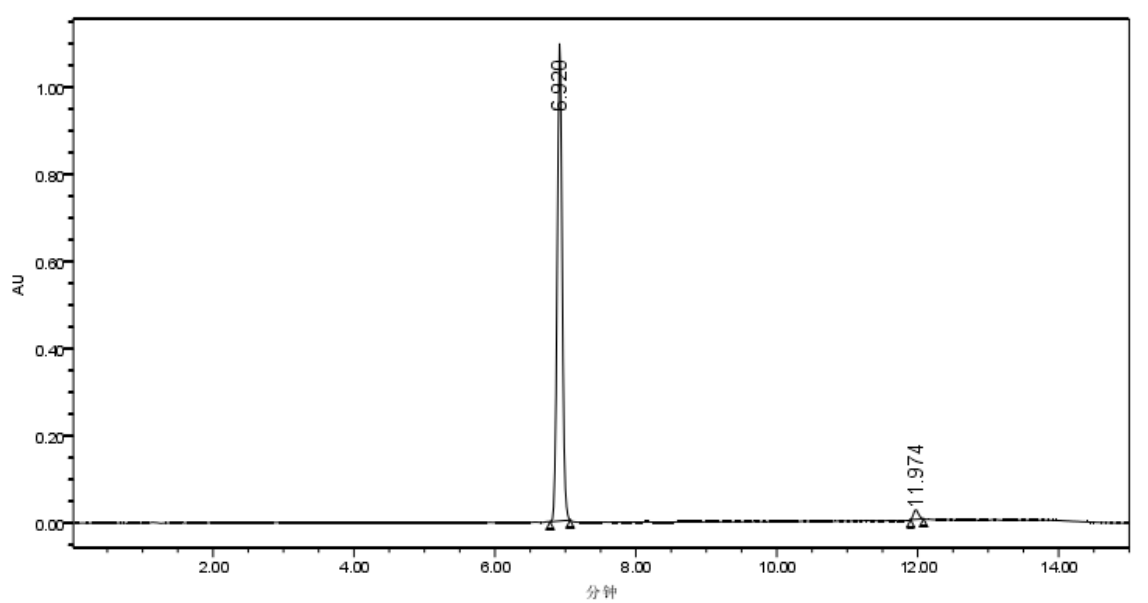


HPLC trace of $\mathbf{2 6}$

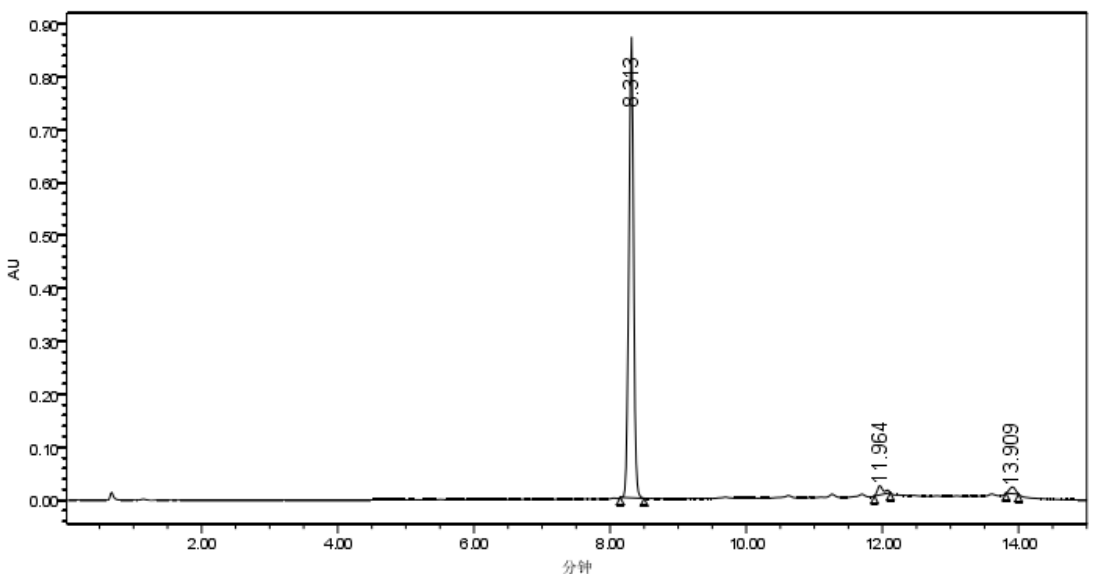

HPLC trace of 27

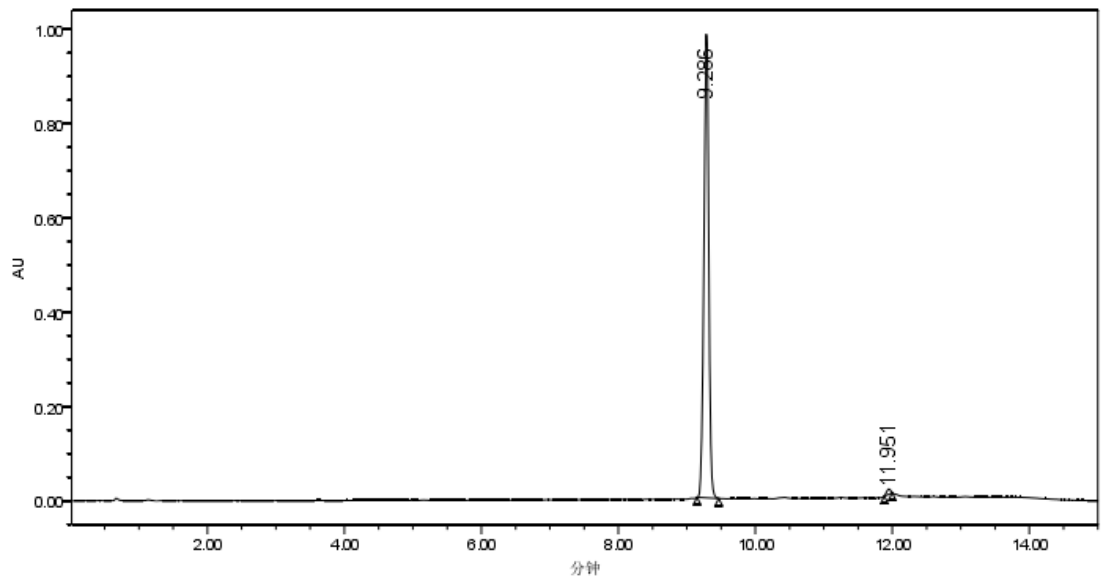

HPLC trace of $\mathbf{2 8}$

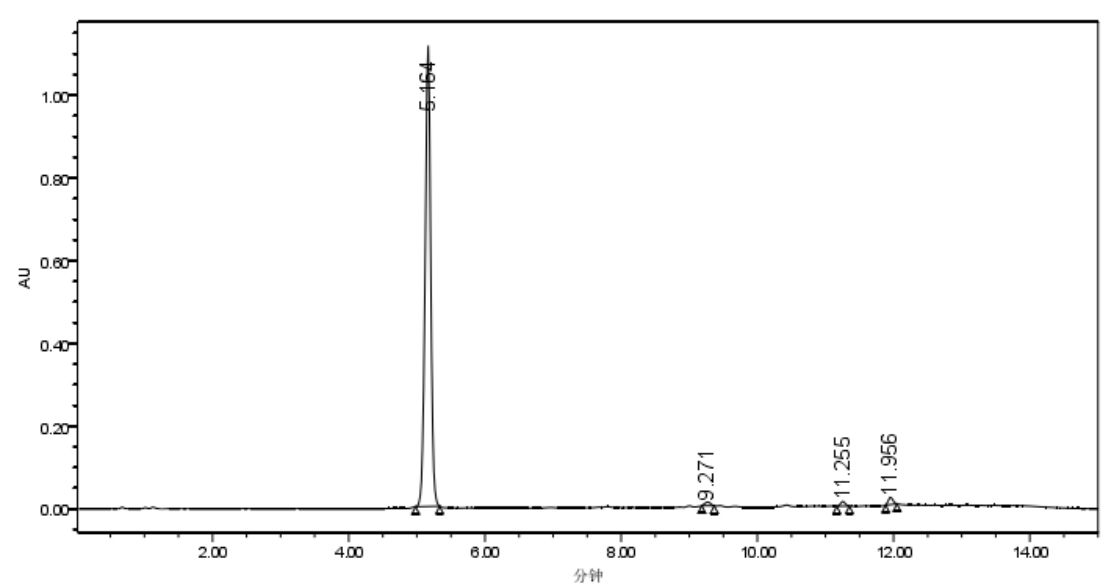


HPLC trace of 29

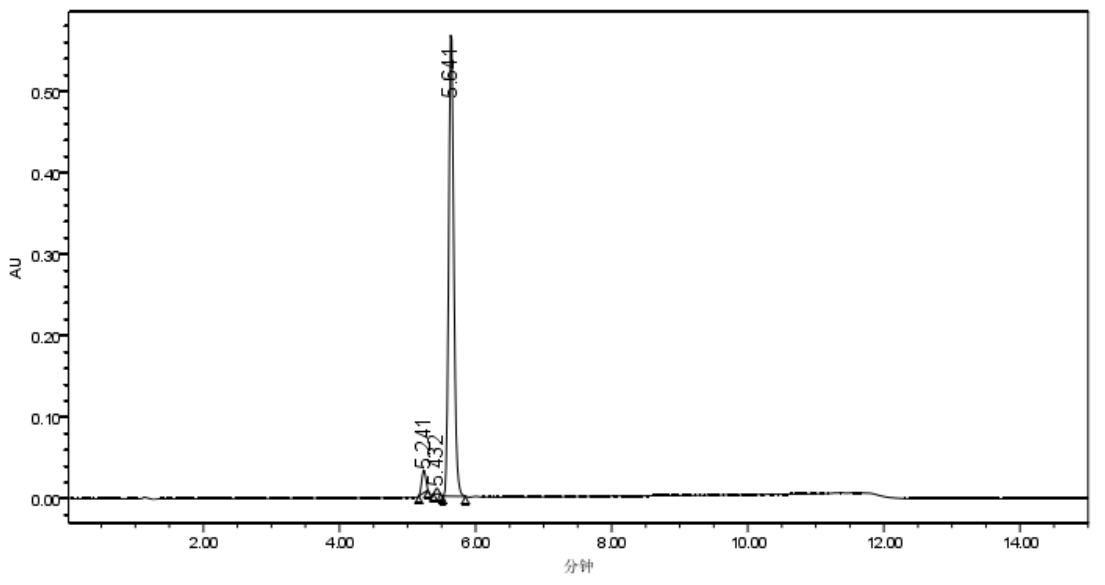

HPLC trace of $\mathbf{3 0}$

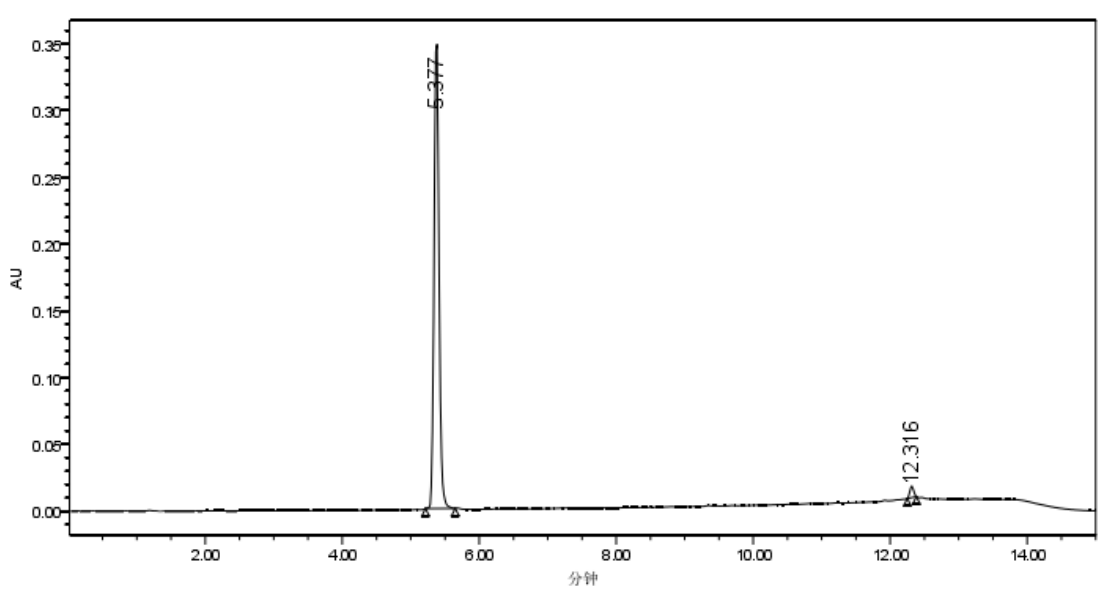

HPLC trace of $\mathbf{3 1}$

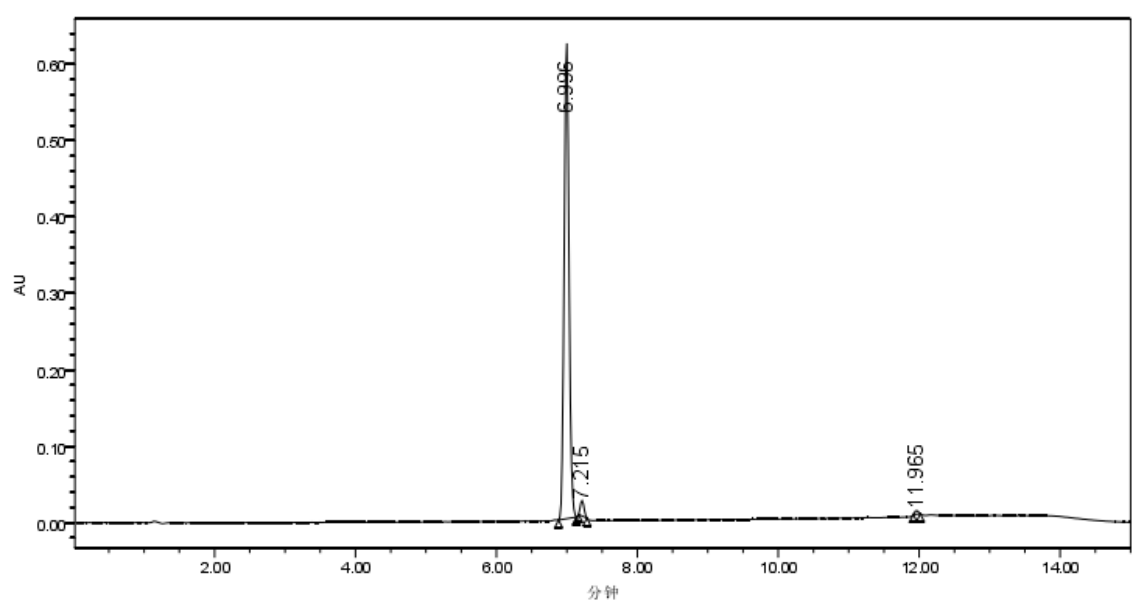


HPLC trace of $\mathbf{3 4}$

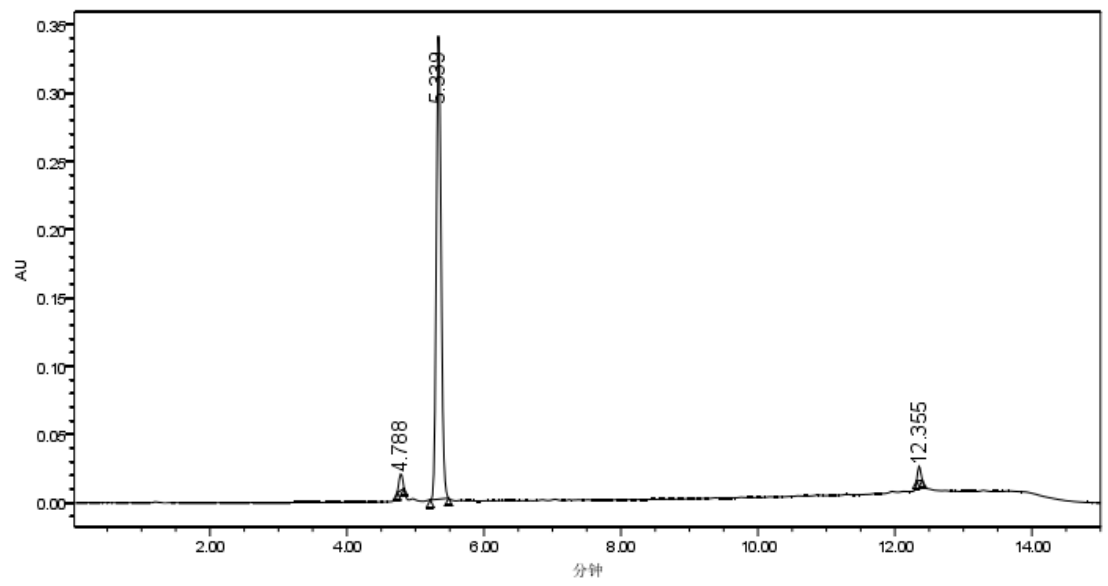

HPLC trace of $\mathbf{3 5}$

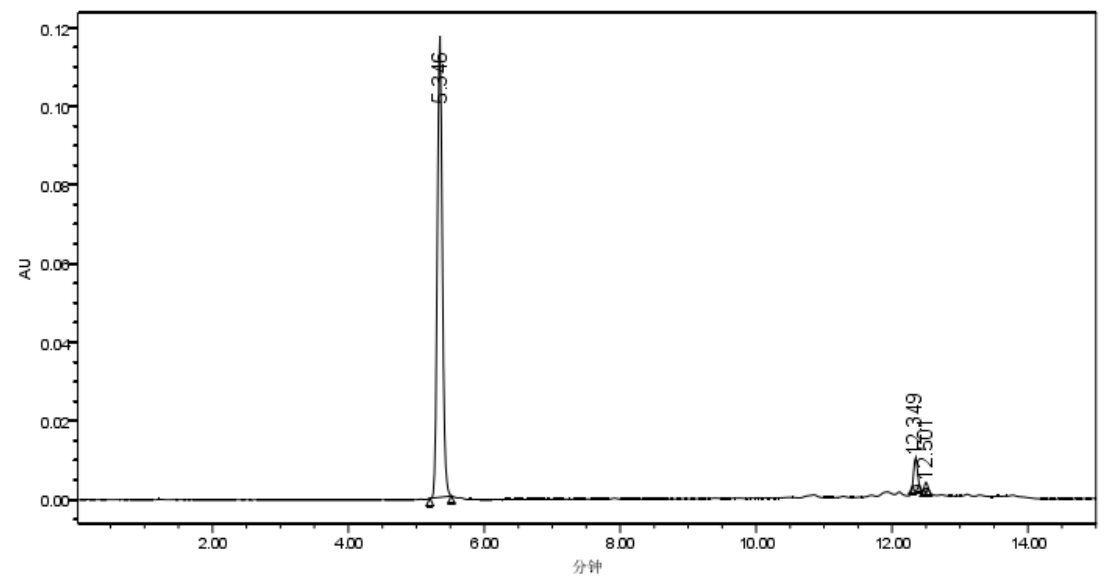

HPLC trace of $\mathbf{3 6}$

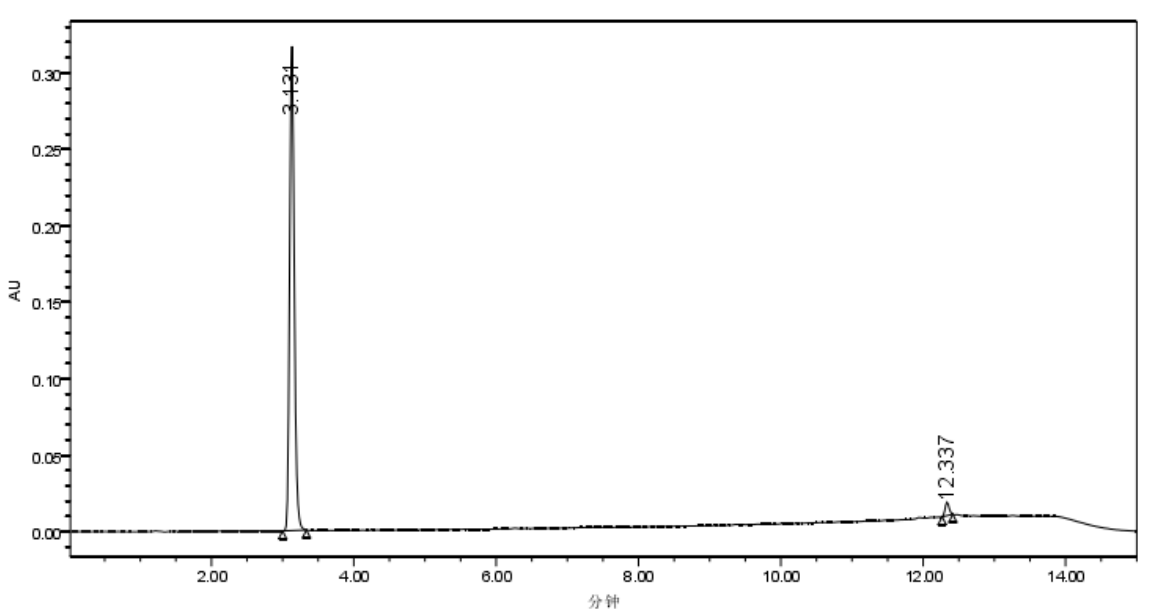


HPLC trace of $\mathbf{3 7}$

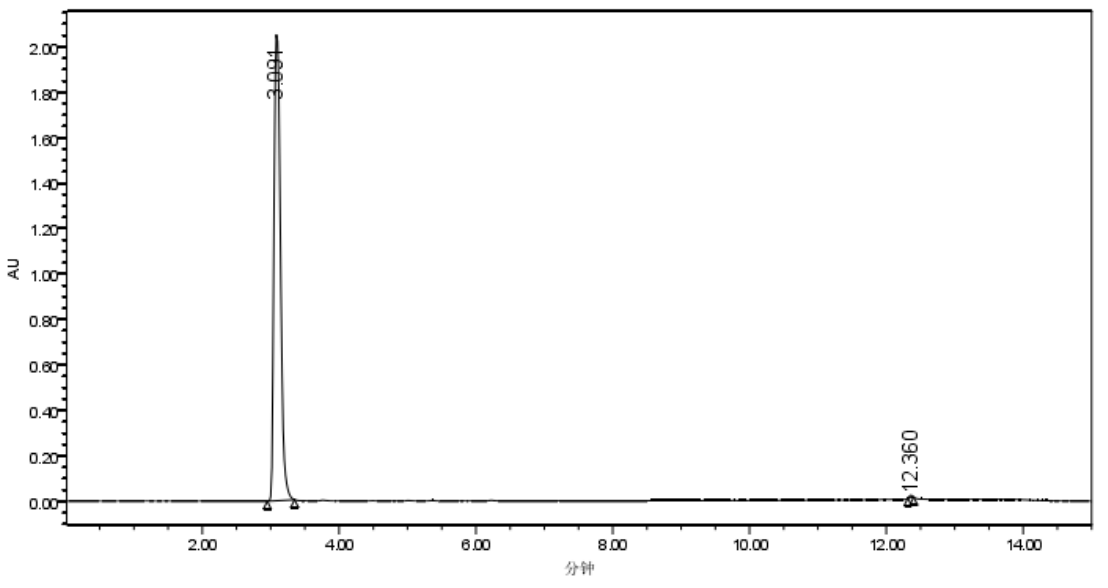

HPLC trace of $\mathbf{3 8}$

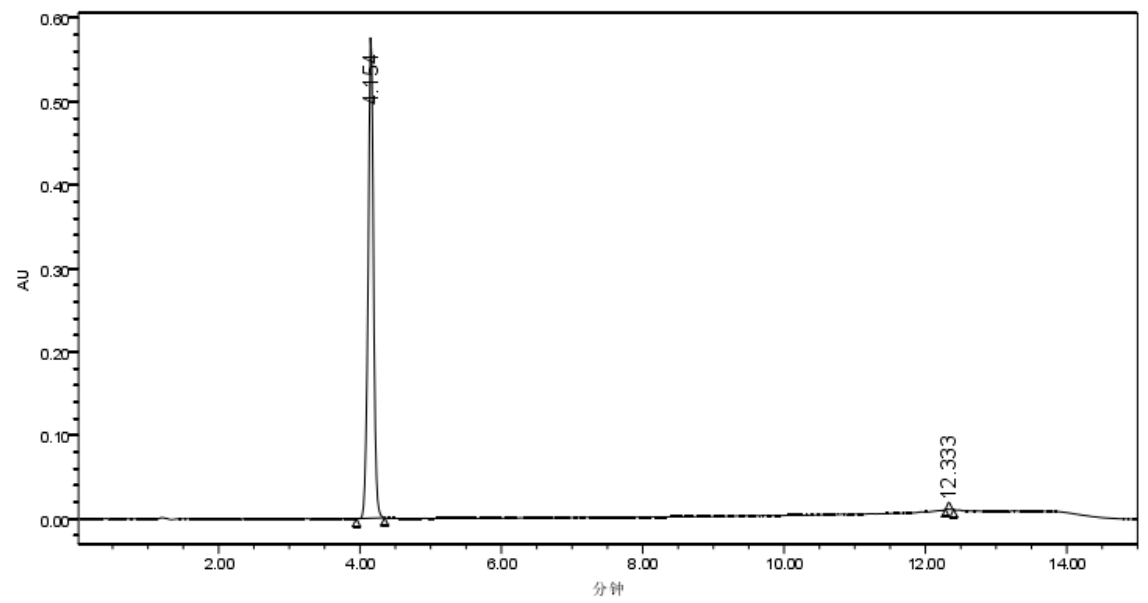

HPLC trace of $\mathbf{3 9}$

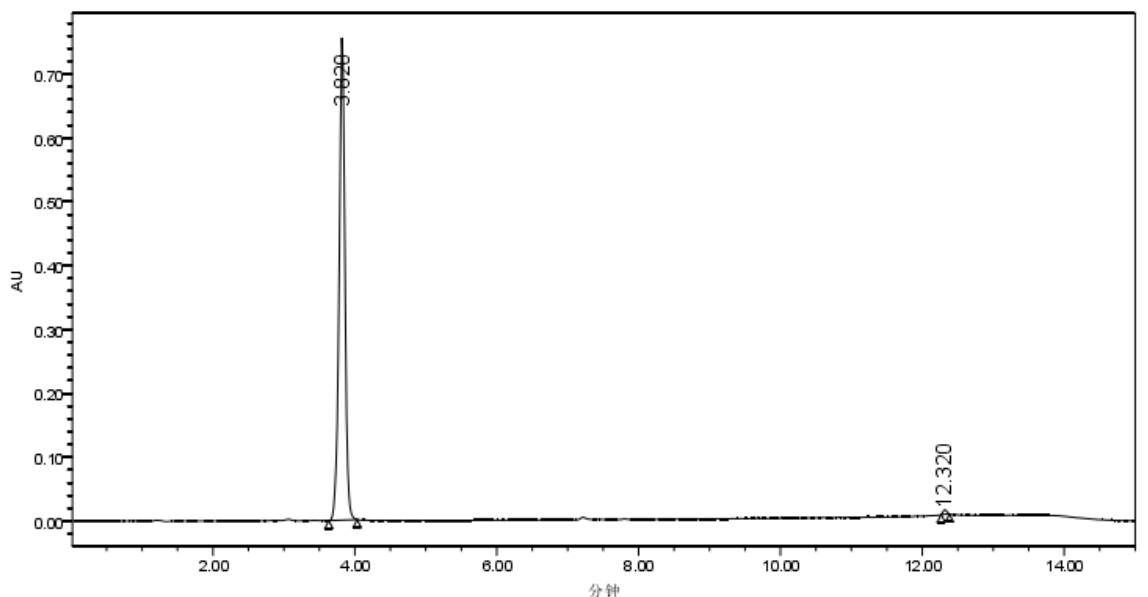

